\title{
THE POTENTIAL OF SEVERAL FLUORIDE-BASED VARNISHES AS REMINERALIZATION AGENTS: MORPHOLOGICAL STUDIES, DENTIN SURFACE HARDNESS, AND CRYSTALLINITY TESTS
}

\author{
SRI ANGKY SOEKANTO*, FADIZA FADILLAH, PUTRI NURAISIYA, FERRY GULTOM, AGOENG T SARWONO \\ Department of Oral Biology, Faculty of Dentistry, Universitas Indonesia, Jakarta, Indonesia. Email: sriangky@ui.ac.id \\ Received: 16 September 2017, Revised and Accepted: 3 October 2017
}

\section{ABSTRACT}

Objectives: This study was conducted to analyze the effects of several fluoride-based varnishes: Sodium diamine fluoride (SDF), nanosilver fluoride (NSF), and propolis fluoride (PPF). Fluoride-based varnish is proven to remineralize and arrest caries progression with minimal side effects. SDF, the gold standard for this study, compared to NSF and PPF to observe the dentin morphology, hardness, and crystallinity test.

Methods: Dentin blocks were allocated and divided into control groups and treatment groups with SDF (38\%), NSF (3.16\%, 3.66\%, and 4.16\%), and PPF (3\%,6\%, and 10\%). The dentin discs were demineralized using a demineralization solution (pH 4.4) for $96 \mathrm{~h}$. Each dentin disc in the treatment group received a topical application of various fluoride-based varnishes and was then subjected to pH cycling for 8 days. The surface morphology of dentin was observed by a scanning electron micrograph (SEM), dentin hardness was analyzed by a Vickers microhardness tester, and the crystal characteristics of dentin blocks were investigated by X-ray diffraction (XRD).

Results: This study showed crystal fluorapatite on the dentin surface of SDF and NSF. There was an amorphous layer on the dentin surface of PPF (10\%) detected when using SEM. The Vickers hardness number of dentin increased after the application of SDF, NSF, and PPF. XRD revealed precipitates of apatite compounds, calcium compounds, and metal compounds in the treatment groups in higher concentrations than in the control (demineralized) group.

Conclusion: It was concluded that SDF, NSF, and PPF were effective for dentin remineralization. Hence, NSF and PPF fluoride-based varnishes are promising as anticariogenic agents.

Keywords: Nanosilver fluoride, Propolis fluoride, Silver diamine fluoride, Remineralization, Dentin morphology, Crystallinity test, Dentine hardness. (c) 2017 The Authors. Published by Innovare Academic Sciences Pvt Ltd. This is an open access article under the CC BY license (http://creativecommons. org/licenses/by/4. 0/) DOI: http://dx.doi.org/10.22159/ijap.2017.v9s2.15

\section{INTRODUCTION}

Based on the data collected for basic health research from the Ministry of Health, the percentage of dental and mouth problems in Indonesia, in 2007 , reached $23.3 \%$ and increased in 2013 to $25.9 \%$. The decay missing filling tooth index in 2013 reached 4.6, which means that tooth decay in the Indonesia population affected 460 teeth per 100 people [1]. Fluoride is a natural mineral that can inhibit the development of dental caries. Fluoride plays an important role in inhibiting demineralization and improving natural remineralization [2]. The topical application of fluoride is one of the protective factors affecting remineralization $[2,3]$.

Fluorapatite, component of tooth enamel, has a better subunit structure that is not easily soluble until the $\mathrm{pH}$ reaches 4.5. Fluoride is available in a variety of dosage forms including sodium diamine fluoride (SDF), nanosilver fluoride (NSF), and propolis fluoride (PPF) [4-14]. Previous studies using SDF have shown that SDF consists of silver (Ag) and fluoride (F); silver acts as an antimicrobial agent and fluoride plays a role in enhancing remineralization as a strong anticaries agent [11]. SDF causes black stains on the teeth, so NSF is formulated as an alternative agent alongside SDF in dealing with dental caries. NSF has components similar to SDF, including silver (in the form of nanoparticles) and fluoride [12].

Currently, Universitas Indonesia is developing a natural fluoridebased varnish: PPF that in this study was tested for its ability to arrest caries progression compare to SDF and NSF, which are silver based. The content of flavonoids in propolis can inhibit the activity of glucosyltransferase, which plays a role in the formation of biofilm [15].
This study observed the dentin morphology, the increase in dentine hardness, and the crystallinity test to determine the potential of SDF, SNF, and PPF as anticaries agents.

\section{METHODS}

This study was approved by the Ethical Committee of the Faculty of Dentistry, Universitas Indonesia. This was an experimental laboratory study using dentin blocks separated into several groups: Positive control groups using demineralized dentin blocks, negative control groups using dentin blocks without a demineralized process, and treatment groups that received topical applications of 38\% SDF, 3.16\% and $4.16 \%$ NSF, and 3\% and 10\% PPF. Dentine blocks for the negative control group received no demineralized treatment, while the positive control group and treatment groups were demineralized for $96 \mathrm{~h}$ followed by a pH cycling process 6 times a day for 8 days.

This process aimed to create a similar environment to the oral cavity. All treatment groups were fixed in $4 \%$ formaldehyde, rinsed with distilled water, and dried using ethanol. Then, specimens were dried in a desiccator and coated with a conducting material. The surface morphology was assessed using scanning electron micrograph (SEM) in $5 \mathrm{kV}$ high vacuum mode. The dentin initial microhardness was tested before being soaked in a demineralization solution using a Vickers microhardness tester with $50 \mathrm{~g}$ of force in $10 \mathrm{~s}$.

After that, the specimens were demineralized in $4.4 \mathrm{pH}$ for $96 \mathrm{~h}$ followed by deionization and drying. The dentin initial microhardness was tested again using a Vickers microhardness tester under a light 
microscope. Each demineralized specimen was varnished, rinsed, and dried followed by a pH cycling process. The dentin surface hardness after treatment was tested using a Vickers microhardness tester, and then, all Vickers hardness number (VHN) data were analyzed.

The crystallinity tests were conducted using X-ray diffraction (XRD). All specimens were placed in a goniometer, and the measurement parameters were configured in the software followed by XRD setting $\left(40 \mathrm{kV}, 30 \mathrm{~mA}, 1 \mathrm{~s}\right.$ step scanning speed, $0.02^{\circ}$ step size). An X-ray diffractometer was used so that all X-rays would radiate all the specimens. The diffraction results were shown on the computer screen

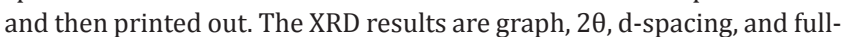
width at half-maximum (FWHM) values.

\section{RESULTS}

The diameters of dentine tubules from the SEM results are shown in Fig. 1. NSF showed dentinal tubules wider than SDF and PPF. Using propolis with a $10 \%$ concentration produced the dentinal tubules almost as wide as SDF.

The results of dentine hardness tests before and after demineralized and after the application of SDF, NSF, and PPF are shown in Fig. 2, which shows the difference in mean values for each group. After demineralization, dentine hardness decreased from 64.82 \pm 8.15 VHN to $10.32 \pm 2.27$ VHN in SDF $38 \%$. The NSF $3.16 \%$ group had an initial dentin hardness of $62.88 \pm 8.42 \mathrm{VHN}$, which then decreased to $9.86 \pm 1.49$. NSF $4.16 \%$ had an initial dentin hardness of $66.16 \pm 4.53$ VHN, which decreased to $10.98 \pm 1.53$ VHN. Furthermore, in PPF $3 \%$ and $10 \%$ with an initial dentin hardness of $66.2 \pm 1.77 \mathrm{VHN}$ and $66.68 \pm 4.51$, respectively, VHN decreased to $10.06 \pm 0.84 \mathrm{VHN}$ and $11.44 \pm 2.33 \mathrm{VHN}$.

After being dissolved in the demineralization solution, SDF, NSF, and PPF were applied to the specimens. The results showed that in SDF, the dentin hardness increased from $10.32 \pm 2.27 \mathrm{VHN}$ to $11.98 \pm 1$.93. In NSF $3.16 \%$, the hardness increased from $9.86 \pm 1.49 \mathrm{VHN}$ to $12.22 \pm 1.94 \mathrm{VHN}$, while the $4.16 \%$ group increased from $10.98 \pm 1.53 \mathrm{VHN}$ to $12.36 \pm 0.80$ VHN. In the PPF $3 \%$ group, the dentin hardness increased from $10.06 \pm 0.84$ VHN to $12.52 \pm 1.08$ VHN. The PPF $10 \%$ group increased from $11.44 \pm 2.33 \mathrm{VHN}$ to $13.56 \pm 0.96 \mathrm{VHN}$.

Based on a normality test using Shapiro-Wilk, the data on initial dentin hardness before and after demineralization are not normally distributed $(\mathrm{p}<0.05)$, while after the application of SDF, NSF, and PPF, the data are normally distributed $(p>0.05)$. The Friedman test was conducted to show the significance of decreasing and increasing dentin surface hardness values on each group, and the Wilcoxon statistical test was then performed to show the significance of each treatment group (SDF, NSF, and PPF).

The Kruskal-Wallis test was conducted to show the significance value of dentin initial hardness before and after demineralization and after the application of SDF, NSF, and PPF. Post hoc Mann-Whitney analyses were performed as a continuation of the Kruskal-Wallis test.

Fig. 3 shows the average mean of overall dentine surface hardness in the pre- and post-demineralization process and after the application of SDF, NSF, and PPF in varying concentrations.

The statistical tests showed that there was a significant difference in dentin hardness $(\mathrm{p} \leq 0.05)$ after the application of NSF $3.16 \%(\mathrm{p}=0.042)$ and PPF $10 \%(p=0.043)$ compared to the after demineralization values. However, there was no significant difference in dentin hardness after the application of SDF ( $\mathrm{p}=0.138)$, NSF $4.16 \%$ ( $\mathrm{p}=0.225)$, and PPF $3 \%(\mathrm{p}=0.080$ ) compared to the after demineralization values. The results of the statistical tests showed that there was no significant difference in initial dentin hardness after the application of SDF, NSF, and PPF ( $p=0.909)$.

The dentin hardness values of all groups after demineralization also did not show any significant difference $(p=0.390)$. However, there were

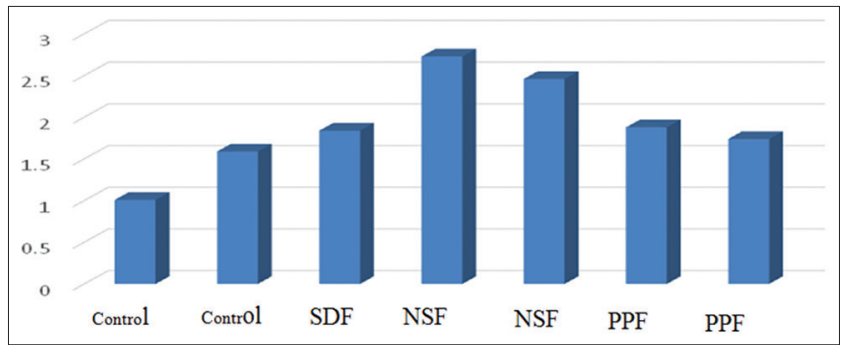

Fig. 1: The mean values of dentine tubule diameters

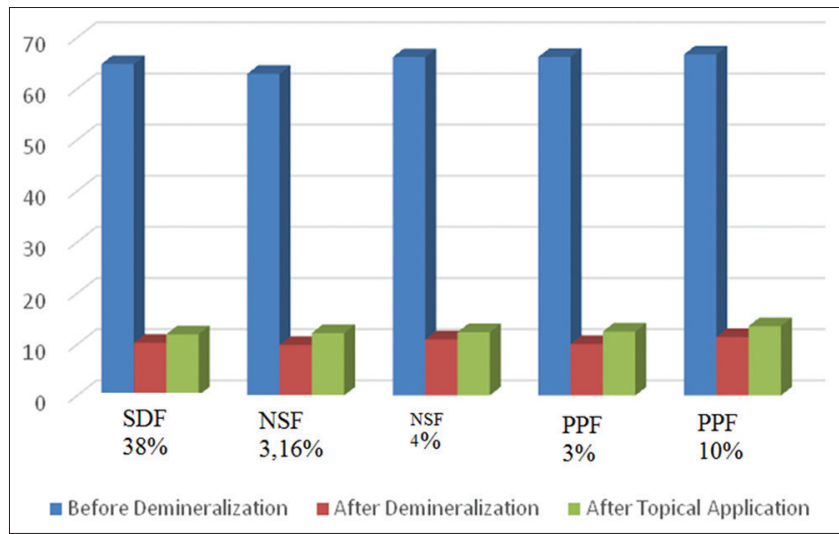

Fig. 2: The mean values of dentine hardness Vickers hardness number

significantly different hardness values after the application of SDF, NSF, and PPF to the specimens ( $\mathrm{p}=0.013$ ).The results of the crystallinity test were obtained from XRD. Using this test, the ability of several fluoride-based varnishes to maintain the crystallinity of the enamel can be observed. The diffraction was processed using automated powder diffraction so that the crystal pattern could be formed. The pattern was then adjusted to the International Centre for Diffraction Data (ICDD) database, and XRD pattern analyses were conducted using the X'Pert High Score Plus application.

The results of the analysis were as follows: There was an image of an XRD peak showing the type of crystal compound in the specimen. This diffraction peak represents the function of the crystal atom position. The peak intensity showed the intensity of the diffracted crystal compound, but it did not show the number of certain crystalline compounds in the specimen. The shape and width of the diffraction peak, also called the FWHM form, can be used to determine the degree or quality of crystallinity and the size of crystallites. The smaller the FWHM, the better the crystallinity. The improved level of crystallinity indicates a normal crystal form and increased crystal homogeneity.

Fig. 4 shows the results of the diffraction pattern formed from the dentin block group. After the search and/or match between XRD graphs and ICDD data, it can be concluded that there were three types of crystalline compounds that are diffracted: A (calcium compound), b (apatite compound), and c (metal compound). Calcium compounds were generally seen at angles of $2_{\theta}=250-270$. Apatite compounds were seen at angles of $2 \theta=310-330$. Meanwhile, the metal compound was generally seen at angles of $2 \theta=460-530$. The type of compound at each peak may vary depending on the crystal formed. In this study, the compounds observed were (a) calcium compounds $\left(\mathrm{CaF}_{2}\right.$ and $\left.\mathrm{CaOH}\right)$, (b) apatite compounds $\left(\mathrm{Ca}_{10}\left(\mathrm{PO}_{4}\right)_{6} \mathrm{OH}_{2}\right.$ and $\left.\mathrm{Ca}_{10}\left(\mathrm{PO}_{4}\right)_{6} \mathrm{~F}_{2}\right)$, and (c) metal compounds $\left(\mathrm{Ag}_{3} \mathrm{PO}_{4}\right)$. One apatite peak on all specimens has a relative intensity of $100 \%$. However, the FWHM values for each specimen show varying numbers depending on the intervention given. The XRD graph can also be interpreted through FWHM values and forms. 


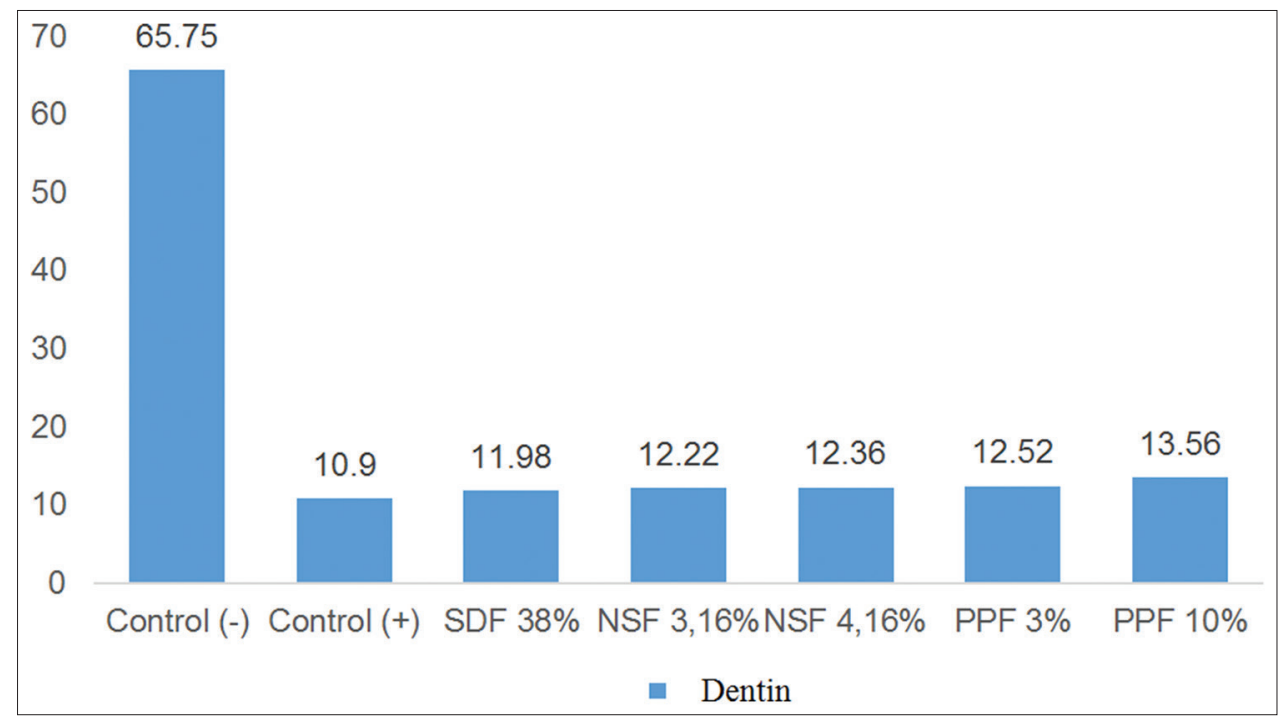

Fig. 3: The average mean of all dentin surface hardness

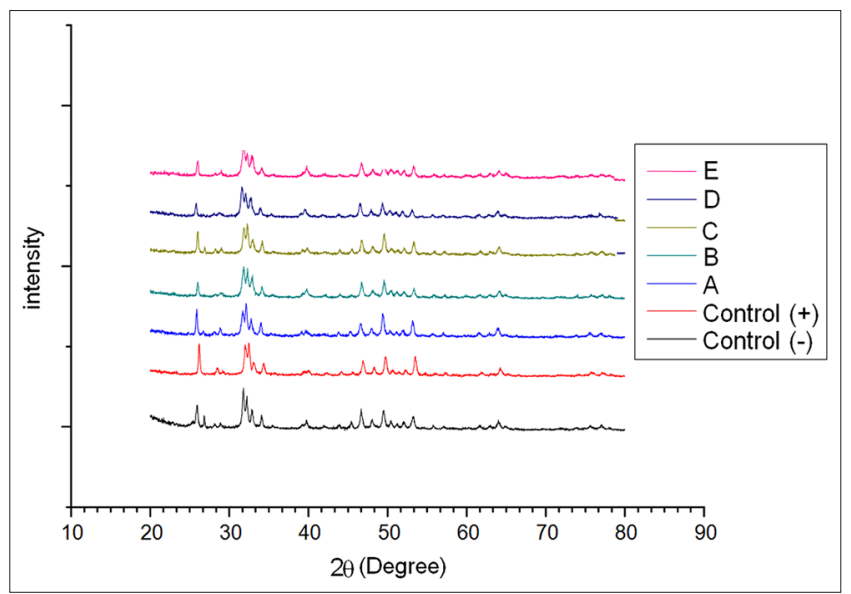

Fig. 4. X-ray diffraction patterns, (a) sodium diamine fluoride $38 \%$, (b) nanosilver fluoride (NSF) $3.16 \%$, (c) NSF $4.16 \%$, (d) propolis fluoride (PPF)3\%, (e) PPF 10\%

Fig. 5 shows the FWHM values in all specimens, especially apatite compounds that have $100 \%$ relative intensity. The graph also shows that the lowest FWHM value was in the negative control group. The treatment group showed lower FWHM values than the positive control group with SDF, NSF $3.16 \%$, PPF 3\%, and PPF 10\%. The biggest difference in FWHM values occurred between the positive control groups with PPF $3 \%$, for which the difference between the two groups was 0.40 .

The FWHM shape also related to the quality of the crystals in all specimens. As shown in Fig. 5, the FWHM form in the negative control group was pointy and sharp, and it was also closely related to the low FWHM value. Meanwhile, in the positive control group, the shape of the FWHM form becomes split and irregular so that the crystal surface was not as smooth in the negative control group. In the treatment group, the FWHM form was similar to the positive control groups.

Figs. 6-10 show the FWHM values in SDF, NSF (3.16\% and 4.16\%), and PPF (3\% and $10 \%)$. The graph shows that NSF $4.16 \%$ produced the highest diffraction of calcium.

Fig. 11 shows SEM images of the control, SDF, NSF 4.16\%, and PPF $10 \%$ groups. This image shows the dentin surface of control without a demineralized process (a) and with a demineralized process only (b).
The crystal fluorapatite on the dentin surface can be seen in SDF and NSF (d). There was an amorphous layer on the dentin surface of PPF $10 \%$ (e) seen when using SEM.

\section{DISCUSSION}

The diameter of dentin has become an important parameter in the fluid diffusion and transfer through dentine associated with caries development [16]. Dentin permeability is closely related to these parameters, as the smaller the diameter of the dentin, the more permeability decreases. Dentin permeability affects fluid movement along the dentin tubules. In caries dentine, there are several factors associated with decreasing dentin permeability, such as natural appositional growth of intratubular dentine, deposition of calcium phosphate, mineral deposits, collagen fibrils, the presence of bacteria, and the formation of smear layers on dentine surfaces [17]. The low permeability of dentine caries may protect the pulp and reduce the amount of chemical irritation when further caries occur [18]. The increased tubular diameter of dentin occurs due to acid exposure during the demineralization process, which dissolves mineral present in the intertubular and peritubular dentine [17]. The mean value of dentin diameter at negative control is $1.01 \pm 0.2 \mu \mathrm{m}$. Dentin tubule diameter decreased in the negative control group due to being covered by a smear layer. A smear layer is an aggregation of organic substances or debris from the process of cutting the dentin specimens. The value in positive control groups showed an increase in dentin diameter to $1.59 \pm 0.8 \mu \mathrm{m}$ due to exposure to an acidic demineralization solution, thus dissolving the smear layer.

Based on SEM results from SDF, there was an increase in the diameter of dentinal tubules after demineralization from $1.59 \pm 0.8 \mu \mathrm{m}$ to $1.84 \pm 0.2$ $\mu \mathrm{m}$. There is no decreased permeability in the dentinal tubules because there is no increase in peritubular dentine. However, the formation of fluorapatite crystals that cover the dentinal tubules can inhibit the movement of bacteria into the dentinal tubules and improve the process of remineralization. In NSF, $3.16 \%$ and $4.16 \%$ showed the formation of fluorapatite crystals. Based on the fluorapatite crystals shown in the SNF group, it can be stated that SNF has the same effect in inhibiting demineralization and increasing the hardness of the demineralized dentin. Based on the study of Santos et al. (in vivo) related to treating caries in children, it was concluded that NSF is more effective in increasing hardness and inhibiting caries in dentin than in no application in dentin [12]. The SEM results after PPF treatment showed a deposition layer of amorphous products along the surface of the dentin with a closed tubule at concentrations of $3 \%$ and $10 \%$. Propolis is a lipophilic sticky substance that is insoluble in water and can act as a buffer to extend 


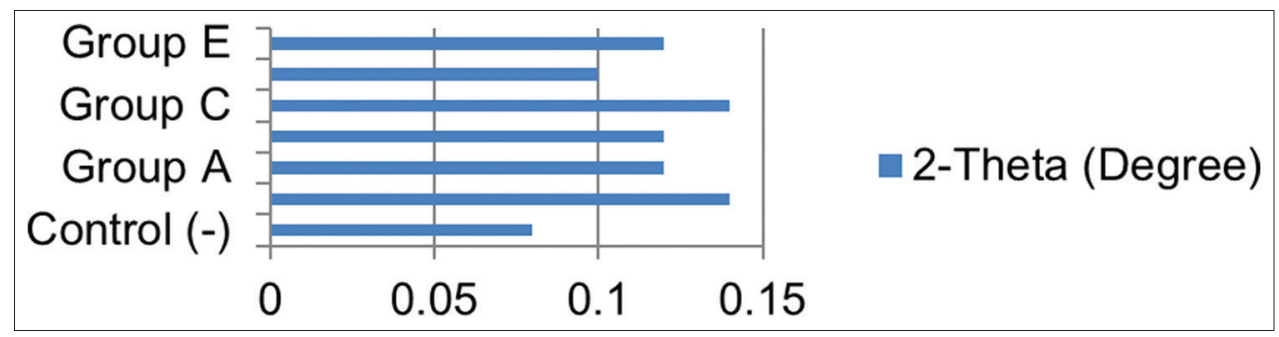

Fig. 5: A comparison of full-width at half-maximum values for all groups: (a) sodium diamine fluoride $38 \%$, (b) nanosilver fluoride (NSF)3.16\%, (c) NSF 4.16\%, (d) propolis fluoride (PPF)3\%, and (e) PPF 10\%

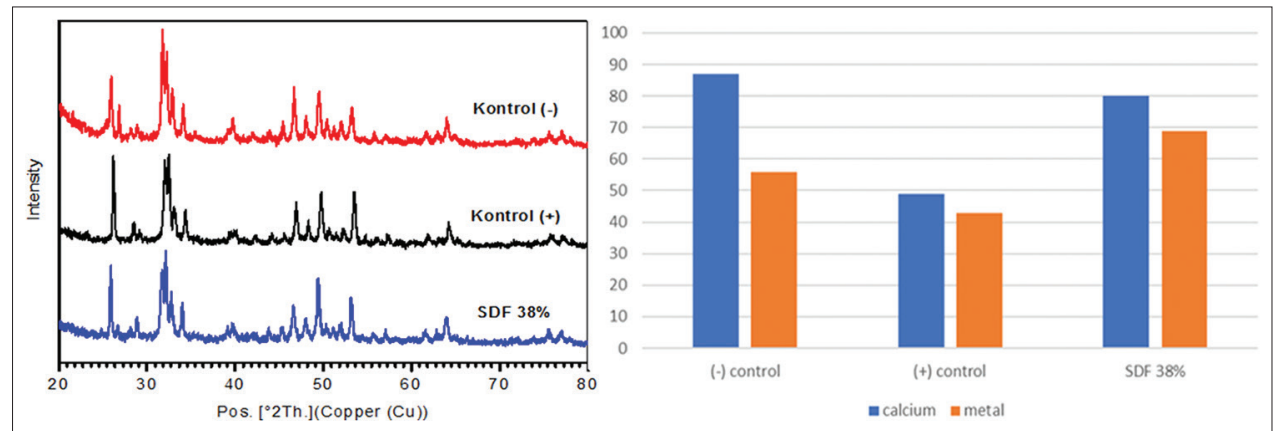

Fig. 6: The difference of X-ray diffraction pattern and comparison of calcium and metal relative intensity in (-) control, (+) control, and sodium diamine fluoride $38 \%$

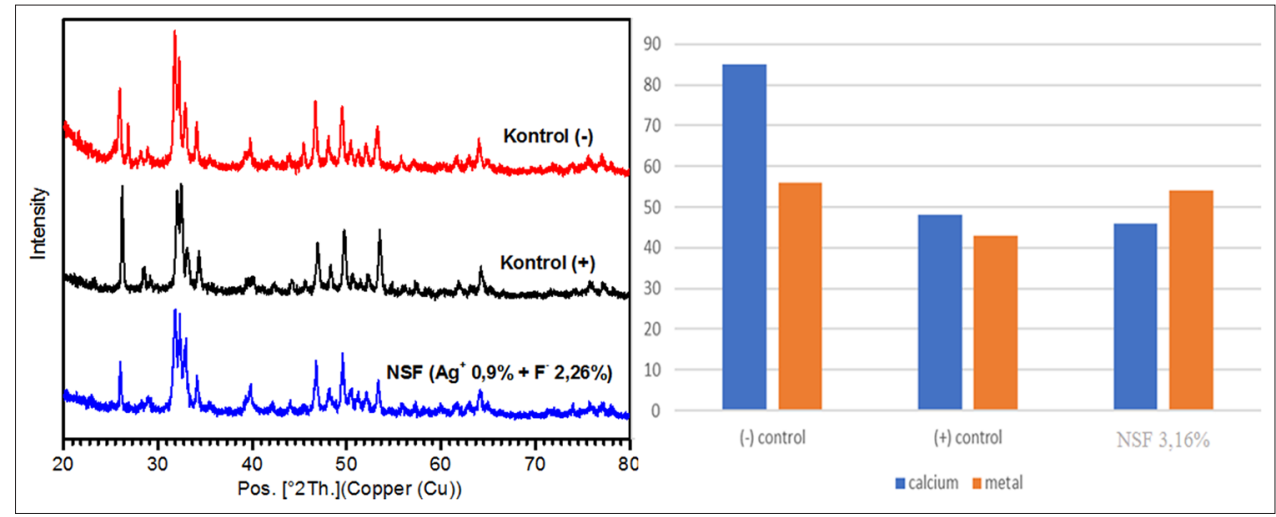

Fig. 7: The difference of X-ray diffraction pattern and comparison of calcium and metal relative intensity in (-) control, (+) control, and nanosilver fluoride $3.16 \%$

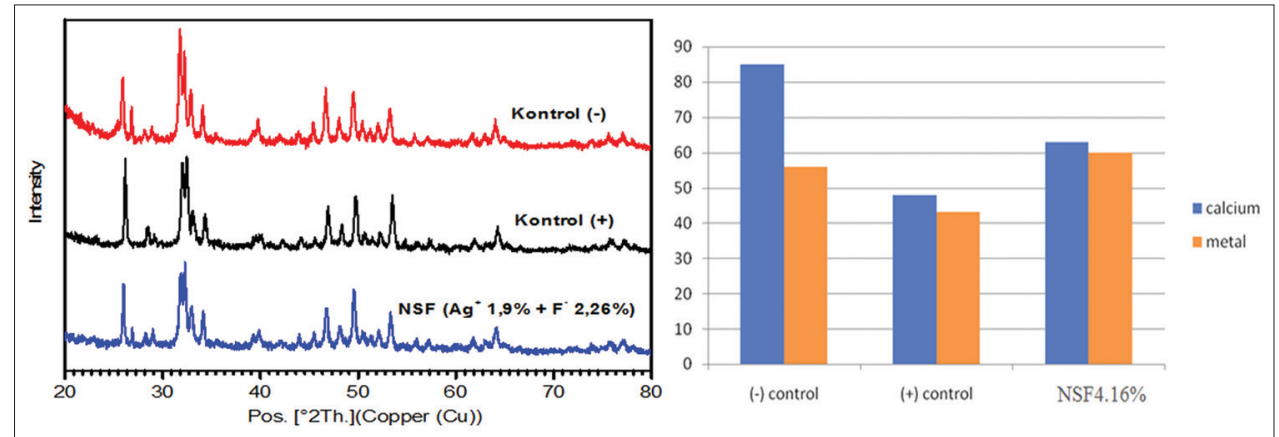

Fig. 8: The difference of X-ray diffraction pattern and comparison of calcium and metal relative intensity in (-) control, (+) control, and SNF 4.16\%

contact time with tooth structure surfaces and increase acid solubility resistance. Propolis has a flavonoid component that interacts with dentine to form crystals that can reduce the flow of movement in the dentine [19]. In addition, the PPF specimens with these two concentrations show a bright picture of the peritubular dentine indicating peritubular dentine thickening. It may be related to the fluoride content of PPF and the $\mathrm{pH}$ cycle process undertaken during treatment, which triggers peritubular and intertubular dentine thickening. 


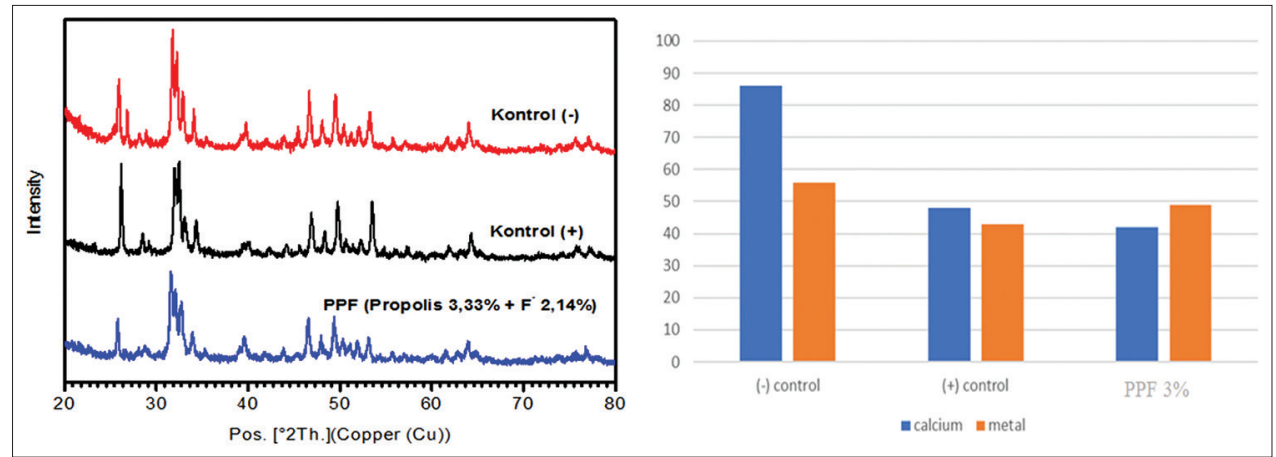

Fig. 9: The difference of X-ray diffraction pattern and comparison of calcium and metal relative intensity in (-) control, (+) control, and propolis fluoride $3 \%$

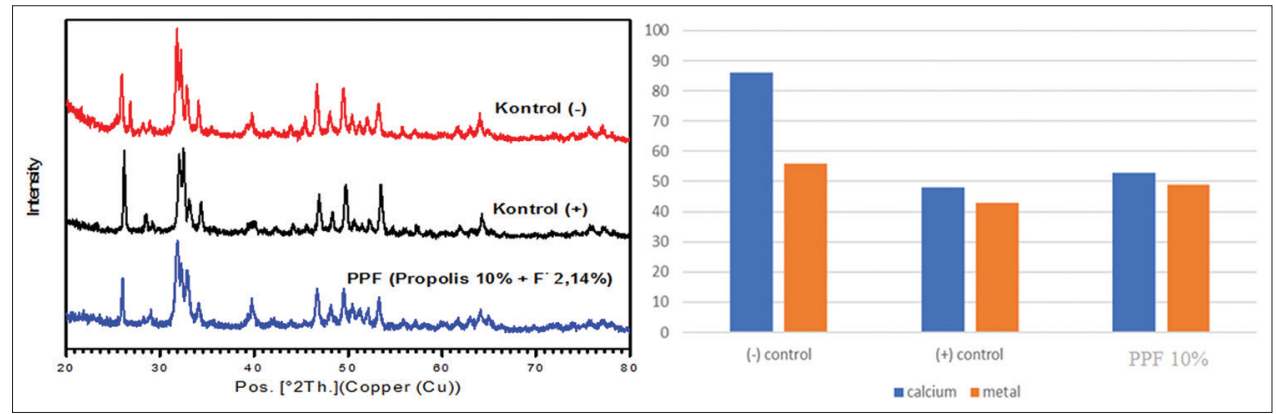

Fig. 10: The difference of $X$-ray diffraction pattern and comparison of calcium and metal relative intensity in (-) control, (+) control, and propolis fluoride $10 \%$

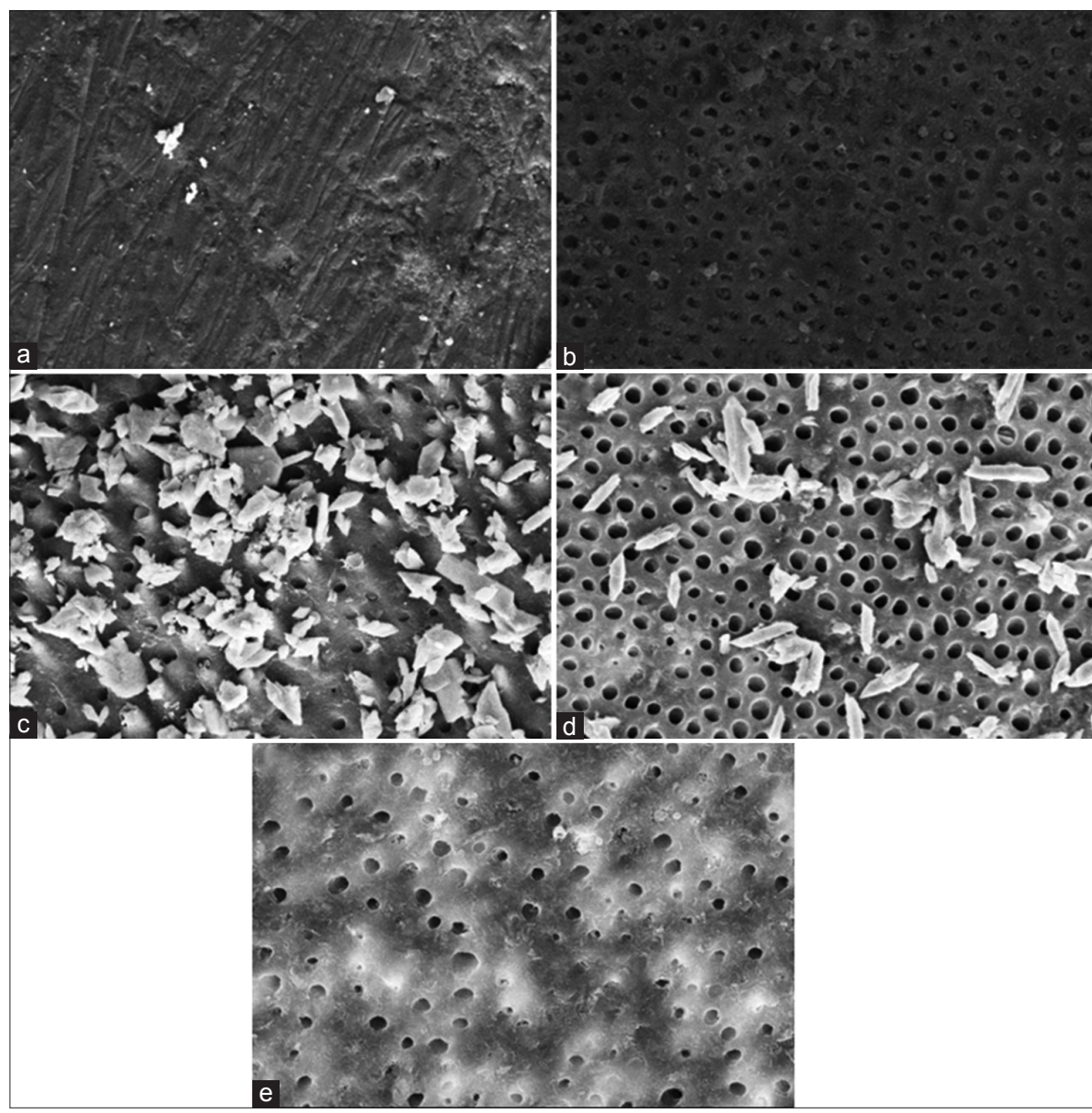

Fig. 11: Scanning electron micrograph images of test, (a) control (-), (b) control (+), (c) sodium diamine fluoride $38 \%$, (d) nanosilver fluoride $4.16 \%$, (e) propolis fluoride $10 \%$ 
There was significant dentin degradation in the five groups after being soaked in a demineralization solution. The degradation value in the five treatments reached $\pm 80 \%$ of the initial dentin hardness. The decrease in hardness is due to the loss of minerals such as calcium, phosphate, and magnesium. In addition, collagen degradation plays a role in mineral deposition [20]. The results of the Mei study showed that SDF had a remineralization effect in increasing the dentin hardness [8], and this study used the same SDF concentration used here. SDF releases fluoride and helps the deposition of silver phosphate retain the mineral content while increasing the hardness of the dentin structure [20]. The remineralization effect in this study was seen from the increase in dentin hardness after the application of SDF. However, the increase in dentin hardness with SDF application did not show significant results.

These data show the remineralization effect of NSF in the form of increased dentine hardness. All concentrations of NSF showed an increasing value after NSF application. The effectiveness of NSF in increasing hardness can be caused by the formation of fluorapatite crystals, as seen in the SEM results. The Friedman test showed that there was a significant increase in dentin hardness in the five treatment groups $(\mathrm{p}<0.05)$. The statistical test results showed a significant increase in the group with NSF $3.16 \%$ and PPF $10 \%(p<0.05)$.

However, the other groups did not show a significant increase ( $p>0.05)$. A Kruskal-Wallis statistical test followed by a post-hoc Mann-Whitney test was performed to see an increase in dentin hardness from the five groups after treatment. The results of the Kruskal-Wallis test showed significant difference in the end hardness value in each group $(p<0.05)$. Differences in value between treatment groups occurred due to differences in the type and concentration of materials.

A decrease in the intensity of crystalline compounds in demineralized teeth compared to teeth without being demineralized was found. These findings also show that the entire treatment group had higher apatite, calcium, and metal crystals than in the demineralized teeth. The greatest crystal peak intensity difference occurs between demineralized teeth and SDF. A significant difference in crystal peak intensity also occurred between demineralized teeth and NSF 3.16\% and between demineralized teeth and PPF $10 \%$. The results of this study are supported by previous research, which concluded that the reaction between hydroxyapatite in a tooth with SDF will produce calcium fluoride and silver phosphate with fluorapatite as the end result [11]. The positive control peak had a highly crystalline image, but the relative intensity was only $47 \%$. This shows that at an angle of $2 \theta=260$, the diffracted crystal is $100 \%$ so that the recorded peak reaches a value of 100 . However, of the 100 diffracted crystals, only $47 \%$ of crystals are pure calcium compounds (in this case $\mathrm{CaOH}$ or $\mathrm{CaF}_{2}$ ), and other residues may contain crystals that are not calcium but are fused during the diffraction process. Therefore, a peak shows only the presence of crystals but is unable to show the purity of the crystals [21].

A peak shows the presence of a crystal of apatite. The sharp, smooth, and uniform shapes of the negative control groups show that the crystals of apatite compounds contained therein are excellent with high homogeneity. Meanwhile, in the negative control group, $\mathrm{Ca}_{10}\left(\mathrm{PO}_{4}\right)_{6} \mathrm{OH}_{2}$ crystals appeared to dominate, while the content of $\mathrm{Ca}_{10}\left(\mathrm{PO}_{4}\right)_{6} \mathrm{~F}_{2}$ was lower. In the positive control group, there was a change in the shape and width of FWHM, the form of which became split and irregular. This was allegedly due to demineralization interventions in positive control groups and is supported by previous research, which concludes that mineral decomposition occurs in demineralized teeth [11].

The calcium in the positive control group was even lower when compared with the negative control group. This is due to the relative intensity of the negative control groups at an angle of $2 \theta=260$ of $86.4 \%$. This shows that the demineralized teeth have lower calcium content than the normal teeth. Meanwhile, the calcium crystals present in the treatment group tend to increase from the positive control group. This was due to the varnish content that triggers an increase in calcium. A comparison of the relative intensity of calcium in this study shows that SDF can increase the intensity of calcium close to the negative control groups. Previous research has shown that the reaction between SDF and hydroxyapatite in teeth will produce $\mathrm{CaF}_{2}$ and $\mathrm{Ag}_{3} \mathrm{PO}_{4}$, and $\mathrm{CaF}_{2}$ content is what triggers the increase in calcium [11].

This study showed that the NSF group has greater calcium intensity than positive control groups, but the difference is not significant when compared to SDF. In PPF, the intensity of the calcium is even smaller or relatively the same as the positive control group, and it is influenced by the low calcium content in PPF. This is supported by previous research, which concludes that propolis contains low calcium and fluoride plays a major role in improving remineralization [22]. The metal crystals formed in the treatment group tended to be larger than in the positive control group. Significant differences occurred mainly in the treatment group with SDF; even the intensity of metal compounds contained in the SDF treatment group was greater than in the negative control group. This is suspected to be because SDF contains silver (Ag). In addition, the formation of large amounts of metal crystals in NSF is suspected to be caused by the silver content. Meanwhile, the metal compound on PPF has the same intensity or smaller than the positive control group. This is in accordance with previous research, which indicates that propolis contains a small amount of metal compounds [22]. Moreover, scientists have shifted their interest from chemical or physical methods to biological methods as it does not involve a combination of abusive or toxic chemicals to human health or any involvement of immense machines or equipment [23].

\section{CONCLUSION}

The application of SDF, NSF, and PPF at each concentration showed morphological changes on the dentin surface and may also increase the value of dentine hardness after demineralization. However, this application was not sufficient to maintain normal dentine hardness values against the demineralization process. The application of NSF and PPF effectively increases dentin remineralization, which increases the intensity and quality of apatite crystal compounds. NSF and PPF varnish applications are the groups that showed the best remineralization increase, as seen from the quality of crystallinity.

\section{ACKNOWLEDGMENT}

The publication of this manuscript is supported by Universitas Indonesia.

\section{REFERENCES}

1. Kementerian Kesehatan RI. Infodatin: Situasi Kesehatan Gigi dan Mulut. Jakarta: Pusat Data dan Informasi Kementerian Kesehatan RI; 2014.

2. Mount G, Hume W. Preservation and Restoration of Tooth Structure. $2^{\text {nd }}$ ed. Australia: Knowledge Books and Software; 2005.

3. Alcorn M, Rogo E. Silver diamine fluoride. Am Dent Hyg Assoc 2012;26:18.

4. Libério SA, Pereira AL, Araújo MJ, Dutra RP, Nascimento FR, Monteiro-Neto $\mathrm{V}$, et al. The potential use of propolis as a cariostatic agent and its actions on mutans group streptococci. J Ethnopharmacol 2009; $125: 1-9$

5. Mei ML, Ito L, Cao Y, Li QL, Lo EC, Chu CH. Inhibitory effect of silver diamine fluoride on dentine demineralisation and collagen degradation. J Dent 2013;41:809-17.

6. Chu CH, Mei L, Seneviratne CJ, Lo EC. Effects of silver diamine fluoride on dentine carious lesions induced by Streptococcus mutans and Actinomyces naeslundii biofilms. Int J Paediatr Dent 2012;22:2-10.

7. Mei Ml, Li QL, Chu CH, Lo EC, Samaranayake LP. Antibacterial effects of silver diamine fluoride on multi-species cariogenic biofilm on caries. Ann Clin Microbiol Antimicrob 2013;2:4

8. Mei ML, Li QL, Chu CH, Yiu CK, Lo EC. The inhibitory effects of silver diamine fluoride at different concentrations on matrix metalloproteinases. Dent Mater 2012;28:903-8.

9. Knight GM, McIntyre JM, Craig GG, Mulyani, Zilm PS, Gully NJ. Inability to form a biofilm of Streptococcus mutans on silver fluoride- 
and potassium iodide-treated demineralized dentin. Quintessence Int 2009;40:155-61.

10. Rajendra A, Veitz-Keenan A, Oliveira BH, Ruff RR, Wong MC, Innes NP, et al. Topical silver diamine fluoride for managing dental caries in children and adults. Cochrane Database Syst Rev 2017;7:1-7.

11. Rosenblatt A, Stamford TC, Niederman R. Silver diamine fluoride: A caries "silver-fluoride bullet". J Dent Res 2009;88:116-25.

12. Santos VE Jr, Filho AV, Targino AG, Flores MA, Galembeck A, Caldas AF Jr, et al. A new "silver-bullet" to treat caries in children-nano silver fluoride: A randomised clinical trial. J Dent 2014;42:945-51.

13. Liu BY, Lo EC, Li CM. Effect of silver and fluoride ions on enamel demineralization: A quantitative study using micro-computed tomography. Aust Dent J 2012;57:65-70.

14. De Luca MP, Franca JR, Augusto F, Macedo FF, Grenho L, Cortes ME, Faraco AAG. Propolis varnish: Antimicrobial properties against cariogenic bacteria, cytotoxicity, and sustained-release profile. Biomed Res Int 2014;2014:348647.

15. Koo H, Rosalen PL, Cury JA, Park YK, Bowen WH. Effects of compounds found in propolis on Streptococcus mutans growth and on glucosyltransferase activity. Antimicrob Agents Chemother 2002;46:1302-9.

16. Ghazali FB. Permeability of dentine. Malays J Med Sci 2003;10:27-36.
17. Zhi QH, Lo EC, Kwok AC. An in vitro study of silver and fluoride ions on remineralization of demineralized enamel and dentine. Aust Dent $\mathrm{J}$ 2013;58:50-6

18. Elgalaid TO, Creanor SL, Creanor S, Hall AF. The permeability of natural dentine caries before and after restoration: An in vitro study. J Dent 2007;35:656-63.

19. Hongal S, Torwane NA, Goel P, Chandrashekar B. The effect of $30 \%$ ethanolic extract of Indian propolis on replica of human dentin compared against commercially available desensitizing agent: A methodological SEM study in vitro. Pharmacognosy Res 2014;6:113-9.

20. Shoham AB, Rot C, Stern T, Krief S, Akiva A, Dadosh T, et al. Deposition of collagen Type I onto skeletal endothelium reveals a new role for blood vessels in regulating bone morphology. Development 2016;143:3933-43.

21. Bunaciu AA, Udristioiu EG, Aboul-Enein HY. XRD: Instrumentation and applications. Crit Rev Anal Chem 2015;45:289-99.

22. Huang S, Zhang CP, Wang K, Li GQ, Hu FL. Recent advances in the chemical composition of propolis. Molecules 2014;19:610-32.

23. Menon S, Agarwal H, Kumar SR, Kumar SV. Green synthesis of silver nanoparticles using medicinal plant Acalypha indica leaf extracts and its application as an antioxidant and antimicrobial agent against foodborne pathogens. Int J Appl Pharm 2017;9:42-50. 